strength of sandstone lies partly in the ability of the material to deform elastically: a spectacular demonstration of this can be seen in the Hunterian Museum, Glasgow, where a sandstone slab a few centimetres thick and 2.5 metres long supported at its centre sags by about 20 centimetres at its ends. Plastic deformation of poorly cemented sandstone is also possible by intergranular movement, but such deformation can only occur very slowly and must have been useful in coping with subsidence. In either case many lintels are markedly curved.

An insight into the evolution of particular technologies can be obtained from the analytical study of the composition of the artefacts. This is well illustrated in both metallurgy and ceramics. In the latter case recent X-ray diffraction studies of glasses through the ages have been applied to characterize the opacifying agents used from $1450 \mathrm{BC}$.

To quote as an example a particularly well known object, the white opaque decorations on the Portland Vase are due to $\mathrm{Ca}_{2} \mathrm{Sb}_{2} \mathrm{O}_{7}$ - since antimony oxide was ehiefly used up to the third century AD. Tin oxide was not used until well into the Christian era and arsenic not until the eighteenth century. As an illustration of how it is sometimes necessary to modify ideas in the light of extensive analytical information, it has recently been shown that calcium fluoride is present as the agent in Chinese glass of the seventh to tenth centuries AD, whereas it had been thought for many years that such glasses were not developed until the nineteenth century.

The renovation and preservation of antique objects are of great importance if posterity is to be able to inherit the wealth that has so far been discovered. A report on the work of the British Museum in this field concluded the meeting, describing some of the solutions that have been found in the treatment of both metallic and non-metallic objects. Modern materials have a significant part to play in this work, since the aim is always to enable future workers to be able to improve on any restoration, perhaps by use of new methods and materials that may then be available.

A full account of the meeting will be published in the November edition of the Materials Science Club Bulletin, together with the text of the address by Professor F. C. Frank, this year's recipient of the A. A. Griffith medal. The interest generated by the meeting has resulted in the formation of a group to interchange information and give scientific assistance to field workers. Enquiries from scientists interested in participating will be forwarded to the organizers.

\section{Improving Wheat}

\section{from a Correspondent}

IN recent years it has been possible to develop chromosomally deficient or aneuploid lines among the varieties of the commercial wheat of agriculture (Triticum aestivum). These lines are important, because each chromosome can be marked cytologically and followed in the generations after hybridization. It is this ability which enables the chromosomes of one variety to be replaced, one at a time, by chromosomes from another variety. In this way varieties of wheat which differ by only a single chromosome can be produced; each chromosome substitution can then be assessed for its economic benefits, and varieties better than those in current use may be produced. For this approach to be successful, however, substitution lines must be developed on a large scale, a task beyond the scope of any one research institute, let alone any one worker.

Recently Riley and Law suggested that this difficulty could be overcome by co-ordinating European work with wheat aneuploids, and as a result a conference, supported by the Wates Foundation of the Royal Society, was held earlier this year at the Plant Breeding Institute at Cambridge to investigate the possibilities of co-ordination. During discussion it emerged that most European aneuploid material was still at an early stage, and that the first function of a co-operative would be to establish an information service by way of a newsletter through which contact could be maintained. The ultimate aim, however, should be collaboration at the work level, and a start was made on a project in which four key varieties from different parts of Europe will be involved in a reciprocal substitution programme. The European Wheat Aneuploid Cooperative, as it will be called, includes representatives from twenty-one countries.

As well as discussing collaboration in Europe, the conference heard descriptions of work elsewhere. The history of the development of wheat cytogenetics is to a great degree the history of the development of one variety, "Chinese Spring". E. R. Sears, from the USA, who began the work with "Chinese Spring", gave a description of the development of aneuploid research in his laboratory and of the range of aneuploid material available in this important variety. G. Robbelen, from West Germany, gave an account of the development of a monosomic series-that is, aneuploids deficient for a single chromosome--in the variety "Wachtel" by backcrossing to "Chinese Spring"; this illuminated the great importance of maintaining precise eytological control throughout the backcross programme to avoid the possibility of "univalent shift", a process in which particular monosomics are lost. This need for precise control has also been realized in the substitution programme at Cambridge. Although monosomics can be used, the best technique employs a cytologically recognizable chromosome such as a telocentric. The requisite mono-telocentric lines could be produced relatively quickly if telocentric chromosomes from "Chinese Spring", were substituted concurrently with the development of monosomics.

Other contributions from Europe showed that a total of twenty-six varieties, representing many of the best agricultural varieties, are about to be or are being developed into monosomics. In most cases the monosomics are being developed by backcrossing the variety on to an established set of monosomics. Because this requires at least seven or eight generations of backcrossing, many of the monosomic sets are still at an early stage in their development. But the wide range of varieties being exploited in this way offers an opportunity, albeit at a later date, for an effective study of chromosomal differences at the population level.

\section{Studying the Sea}

\section{from a Correspondent}

OCEANOGRAPHERS are a versatile group. At a recent meeting at the National Institute of Oceanography, representatives of the Challenger Society and the marine laboratories discussed physical oceanography, biology, chemistry, and ship design. 